\title{
A Rare Case: Hair/Thread Tourniquet Syndrome Involving Penis in an Adult Dr. Sumanyu Singh ${ }^{1 *}$, Dr. V. V. Prabhu ${ }^{2}$
}

${ }^{1}$ Junior Resident (General Surgery), Bharati Vidyapeeth Deemed To Be University Medical College and Hospital, Medical College Road, Pune-Satara Road, Dhankawadi, Pune, Maharashtra 411043, India

${ }^{2}$ HOD and Professor Department of General Surgery, Bharati Vidyapeeth Deemed To Be University Medical College and Hospital, Medical College Road, Pune-Satara Road, Dhankawadi, Pune, Maharashtra 411043, India

DOI: $10.36347 /$ sjams.2020.v08i05.014

| Received: 27.04.2020 | Accepted: 04.05.2020 | Published: 14.05.2020

*Corresponding author: Dr. Sumanyu Singh

\section{Abstract}

An 85 year old male came to casualty with complaints of urine leaking from proximal penile stump with penile trauma. History of dribbling of urine present since 1 month for which he himself tied a thread on his penis causing his penis getting partially amputated. Diagnosed clinically and treated by partial penectomy and meatoplasty.

Keywords: Penis, urinary leak, partial penectomy, meatoplasty.

Copyright @ 2020: This is an open-access article distributed under the terms of the Creative Commons Attribution license which permits unrestricted use, distribution, and reproduction in any medium for non-commercial use (NonCommercial, or CC-BY-NC) provided the original author and source are credited.

\section{INTRODUCTION}

Hair-thread tourniquet syndrome (HTTS), coined in 1988 by Barton et al., [1] was recognized by at least the 17th century when a hair was reported as strangulating the glans penis. The Lancet officially published a case as long ago as 1832 [2] and HTTS has subsequently been well-established in medical literature [3].Yet numerous clinicians remain unaware of it

HTTS refers to hair (or textile-threads) getting firmly-bound around an appendage, typically with an end-artery such as a digit, causing a "compartment syndrome-like" situation and the possibility of ischaemic gangrene. There are a number of pseudonyms including tourniquet syndrome and toe tourniquet syndrome.

It is important to distinguish HTTS from congenital constriction band syndrome (amniotic band syndrome, Streeter's dysplasia), the latter being a rare congenital condition that is associated with other musculoskeletal disorders.

\section{Case Presentation}

An 85 yr old male came to casualty with complaints of urine leaking from area where he used to tie rubber band to prevent urine leak form penis tip since last couple of months.
On L/E-

- Dribbling of urine

- Rubber band cutting through penile shaft $1 \mathrm{~cm}$ proximal to corona.

- Distal part of penis hanging with remaining residual skin and corporal bodies

- Oedematous glans

- $0.5 \mathrm{~cm}$ ulcer over ventral aspect of glans

- Proximal urethra orifice could not be identified due to severe edema

- Distal urethra orifice also could not be seen.

- Rubber band cut and removed in casualty

- Patency of urethra checked but catheter could not be negotiated in to proximal urethra in OPD.

- Distal glans urethra could be catheterised.

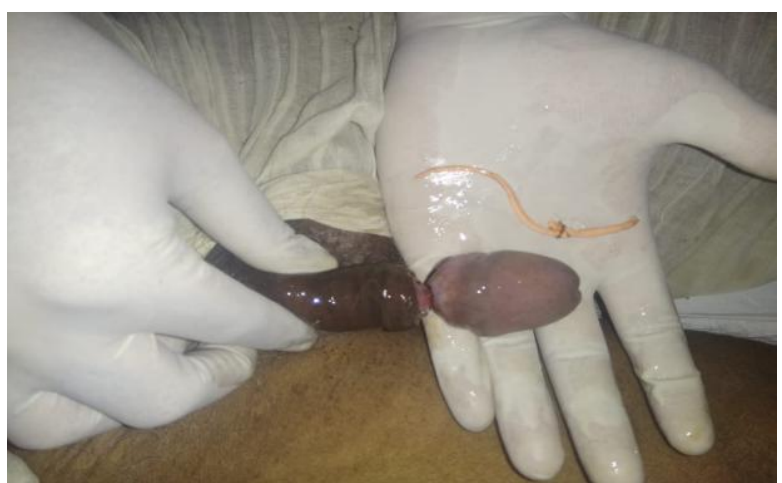




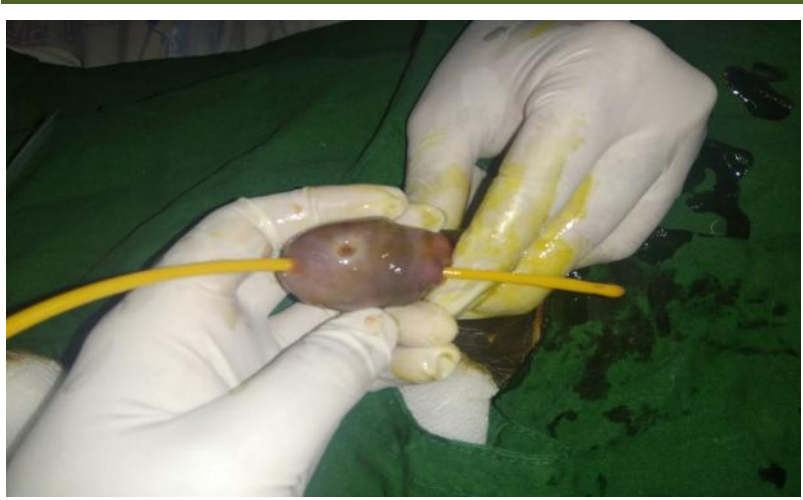

After all routine investigations patients was planned for Partial Penectomy with meatoplasty.

Partial amputation/ excision of loose hanging portion of distal penis with proximal meatoplasty using skin of residual penile shaft. Proximal urethra was normal.

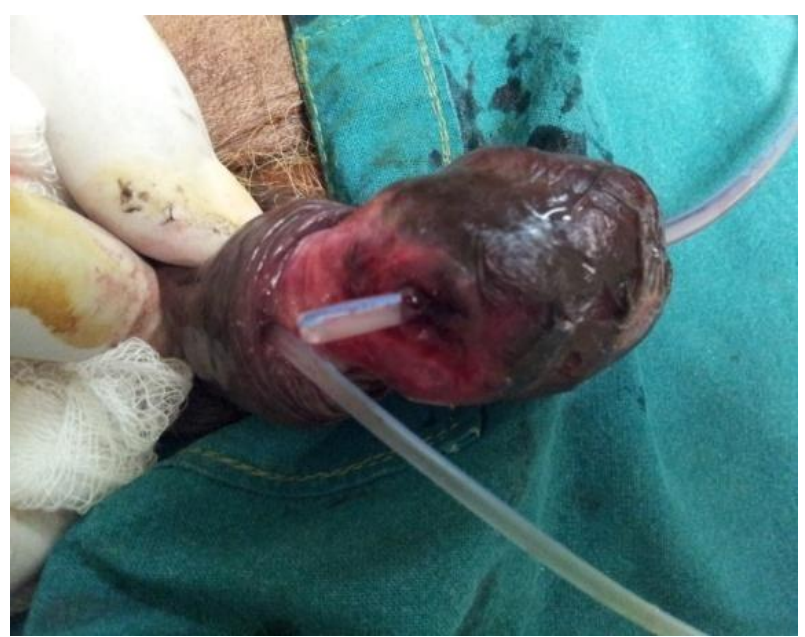

\section{Post Op}

- Urinary incontinence present.

- Hence urethrocystoscopy adviced to assess cause of incontinence

- Proximal end of transected urethra identified with difficulty but once identified, could be catheterised easily - No proximal obstruction.

\section{DisCUSSION}

\section{Etiology}

- Most commonly caused by hair (horse hair).

- Metal band tourniquets

- Thin rubber bands (as in this case)

- Fine threads

- Some call the condition "'constricting tourniquet or hair-thread tourniquet.

- More common in paediatric population

\section{Pathogenesis}

- Circumferential constriction leads to substantial injury
- Lymphatic drainage is initially obstructed

- Increasing edema impedes venous flow

- Venous obstruction further increases swelling which obstructs arterial flow that leads to

a. Tissue necrosis

b. Infection

c. Non healing ulcer

d. Amputation

- As the process continues hair/band cuts through the skin. Commonly involves toes, external genitalia and fingers.

\section{Diagnosis and Management}

- Diagnosis is made clinically

- Remove the constricting band by incising it as soon as possible

a) Occasionally using a curved needle can assist in this.

b) In case of penis, incision needs to avoid the urethra in the corpus spongiosum

- No residual foreign body should remain

- Depilatory cream

a) Cream with thioglycolate and calcium hydroxide or sodium hydroxide

b) Thioglycolate breaks down disulfide bonds of keratin, dissolving the hair.

c) Alkaline component assists with penetration into hair

d) Dissolving time 2.5 to 8 minutes

e) Not to be used on ulcers

f) Does not dissolve cotton, polyester or rayon threads.

- Broad spectrum antibiotics and analgesics are given

- Close follow up.

\section{REFERENCES}

1. Barton DJ, Sloan GM, Nichter LS, Reinisch JF. Hair-thread tourniquet syndrome. Pediatrics. 1988;82(6):925-928.

2. Abel MF, McFarland R., III Hair and thread constriction of the digits in infants: a case report. Journal of Bone and Joint Surgery A. 1993;75(6):915-916.

3. Klusmann A, Lenard HG. Tourniquet syndromeaccident or abuse? European Journal of Pediatrics. 2004;163(8):495-498.

4. Ram RM, William EB, Gary HB. Hair-thread tourniquet syndrome in a cognitively impaired nursing home resident. Advances in Skin \& Wound Care, Sep 2004.

5. Singh V, Singh P, Sharma A, Sarkar J. Acquired constriction ring syndrome as a cause of inconsolable cry in a child: a case report. Cases journal. 2008 Dec;1(1):92.

6. Saad AZ, Purcell EM, McCann JJ. Hair-Thread Tourniquet Syndrome in an Infant with Bony Erosion- a Case Report, Literature Review, and Meta-analysis. Ann Plast Surg, 2006; 57: 447-452. 
7. Bacon JL and Burgis JT. Hair Thread Tourniquet Syndrome in Adolescents: A presentation and review of the literature. Journal Pediatr Adolescent Gynecology, 2005;18:155-156.

8. Okeke LI. Thread embedded into penile tissue over time as an unusual hair thread tourniquet injury to the penis: a case report. Journal of Medical Case Reports, 2008, 2:230.
9. Plesa JA, Shoup K, Manole MD, Hickey RW. Effect of a depilatory agent on cotton, polyester, and rayon versus human hair in a laboratory setting. Ann Emerg Med. 2015 Mar;65(3):256-9.

10. Bannier MA, Miedema CJ. Hair tourniquet syndrome. Eur Journal Pediatr. 2013 Feb;172(2):277. 